\title{
Anti-tumor synergistic activity of nano-chlorophyll with sonophotodynamic on Ehrlich ascites carcinoma in mice
}

\section{Abstract}

Background and objective: Cancer is a major health problem that threatens the life of many peoples with an increasing need for anticancer therapy. The present work aimed to investigate the effectiveness of using sonophotodynamic modality (exposure of infra-red laser as photodynamic) and to the ultrasound as sonodynamic modality in combination with nano-chlorophyll, for cancer therapy through histopathological assessment in Ehrlich ascites carcinoma cell implanted to mice as experimental animals.

Methods: A total of 120 male mice were randomly assigned to 12 treatment groups. Ehrlich ascites carcinoma cell was inoculated subcutaneously in all the experimental mice. When the tumor had grown to about $10 \mathrm{~mm}$ in diameter at day 10 after inoculation, treatments were started. Experimental groups were investigated histopathologically two weeks after treatments.

Results: The histological evaluation revealed that tumors from various treated groups of mice bearing the tumor showed different percentages of necrosis and tumor proliferation based on the type of treatment. Tumor excised from mice receiving sonophotodynamic with nano-Chlorophyll treatment showed a significant increase of necrosis about $15-25 \%$ compared to other groups without nano-chlorophyll as a sensitizer. The group of mice subjected to the combination of photodynamic and sonodynamic therapy in the presence of nano-Chlorophyll, showed large foci distinct necrosis areas $95 \%$ of large distinct foci of necrosis in the tumor and no tumor proliferation.

Conclusion: The anti-tumor activity of nano-chlorophyll in combination with sonophotodynamic therapy for Ehrlich ascites carcinoma in mice was effective.

Keywords: Sonodynamic therapy; Photodynamic therapy; Sonophotodynamic therapy; Nano-chlorophyll; Histopathology.

\section{Introduction}

Cancer can be treated by surgery, chemotherapy, immunotherapy, radiation therapy, and electro-chemo-therapy or other modalities. The choice of therapy method depends upon the location, grade, and stage of the disease. Complete removal of cancer without damage to the rest of other organs or tissues is the objective of any treatment. The effectiveness of chemotherapy is often limited by toxicity to normal tissues in the body. Moreover, radiation can also cause damage to normal tissue. ${ }^{1}$ Therefore, cancer is still causing mortality, and there is a demand for new anti-cancer therapy. ${ }^{2}$ The discovery and identification of new anti -tumor medicine with low or no side effects on the immune system has become a vital goal in many medical research of cancer therapies. $^{3}$ Sonophotodynamic therapy (SPDT, exposure of both infra-red laser and ultrasound) is a safe, non-toxic, and non-invasive way of destroying tumor cells, as well as enhancing immune protective function. Both sonodynamic

${ }^{1}$ Center of Research and Educational Studies, Ministry of Education, Baghdad, I raq

2 Institute of Graduate Studies \& Research, Alexandria University, Egypt.

3 Department of Clinical Analysis, College of Pharmacy, Hawler Medical University, Erbil, Kurdistan, I raq.

${ }^{4}$ Medical Research I nstitute, Alexandria University, Egypt.

* Correspondence: rafel_ar@yahoo.com 
therapy (SDT, exposure of ultrasound), and photodynamic therapy (PDT, exposure of infra-red laser) have been used for years as separate processes. The biological effects of ultrasound may be used for direct tissue destruction of cancer cells or indirectly through enhancing the cell killing effect of other treatments such as radiation and chemotherapy. ${ }^{4,5}$ Nano-chlorophyll (nano-Chl) is a chemical particle of 1 to 100 nanometers in size. Chlorophyll is a green pigment found in plants, which is vital for photosynthesis. Nano-chlorophyll is able to absorb and transfer light energy into the production of free oxygen. ${ }^{6}$ When an ultrasound wave traverses a cell suspension or tissue, the mechanical energy that is transferred can raise the temperature and may cause mechanical and chemical damage to tissues. Histopathology is a field of medical sciences that based on diseased tissues sample sectioning, staining, and evaluation to assess the effect of therapy on patient's tissue. ${ }^{7}$ Ehrlich ascites carcinoma (EAC) is also known as Ehrlich cell, which is originated from the mammary cells of mice. It was originally established as an ascites tumor in mice. The tumor can be cultured in vivo, as well as can be maintained in vitro. EAC is referred to as undifferentiated carcinoma. ${ }^{8}$ This study aimed to achieve an accurate diagnosis and assessment of tissues Ehrlich ascites carcinoma induced to mice based on the evaluation of morphological and structural changes after treating mice by SPDT techniques via exposure to infra-red laser and ultrasound in combination with/without nano-Chl.

\section{Methods}

A total of 120 male Swiss albino mice of 60days old, weighing $20 \pm 2.0 \mathrm{~g}$, were purchased from National Cancer Institute, Cairo University. The animals were housed in plastic cages and were kept under natural light with ad libitum access to food and water. Ehrlich ascites carcinoma (EAC) as mammary cells in origin was inoculated subcutaneously on the left side of all mice. When the tumor had grown to about $10 \mathrm{~mm}$ in diameter at day 10 after inoculation, the experimental treatment was started. The use of experimental animals in the study protocol was carried out in accordance with the ethical guidelines of the Medical Research Institute, Alexandria University (Guiding Principles for Biomedical Research Involving Animals, 2011). The histopathologic features of the 12 experimental groups (each with 10 mice) were investigated after two weeks of treatments. The mice groups included the following:-

Group 1 (G1). Group of tumor bearing mice without treatment as a control group.

Group 2 (G2). Group of tumor bearing mice treated with photosensitizer nano-Chl only.

Group 3 (G3). Group of tumor bearing mice treated with $4000 \mathrm{~Hz}$ Infra-Red Laser (IRL) for 3 minutes.

Group 4 (G4). Group of tumor bearing mice treated with IRL of $7000 \mathrm{~Hz}$, for 3 minutes.

Group 5 (G5). Group of tumor bearing mice treated with intraperitoneal (IP) injection of nano-Chl, and then the tumor site was irradiated with $4000 \mathrm{~Hz}$ IRL.

Group 6 (G6). Group of tumor bearing mice treated with IP injection of nano-Chl, and then the tumor site was irradiated with 7000 $\mathrm{Hz}$ IRL.

Group 7 (G7). Group of tumor bearing mice treated with pulsed ultrasound at a power density of 3 watts $/ \mathrm{cm}^{2}$ for 3 minutes.

Group 8 (G8). Group of tumor bearing mice treated with continuous ultrasound at a power density of 3 watts $/ \mathrm{cm}^{2}$ for 3 minutes.

Group 9 (G9). Group of tumor bearing mice treated with IP injection of nano-Chl, and then the tumor site was treated with pulsed ultrasound.

Group 10 (G10). Group of tumor bearing mice treated with IP injection of nano-Chl, followed by tumor site treated with continuous ultrasound.

Group 11 (G11). Group of tumor bearing mice treated with irradiation of $7000 \mathrm{~Hz}$ IRL for 3 minutes, followed by pulsed ultrasound 3 watts for 3 minutes. 
Group 12 (G12). Group of tumor bearing mice treated with IP injection of nano-Chl, then the tumor site was treated with irradiation of $7000 \mathrm{~Hz} \mathrm{IRL}$ for $3 \mathrm{~min}$, followed by pulsed ultrasound 3 watts for 3 minutes.

The histopathology procedure was based on a sample of Ehrlich tumor tissue of the experimental groups, which were processed and stained by Hematoxylin and Eosin (H\&E) stain. A total of 10 slides per group (one sample from each animal) were investigated for histopathological evaluation. The average percentage of necrosis was calculated for each experimental group from the 10 slides fields examined by light microscopy. For mitotic scores of proliferation, it was assigned a score of 1 to represent 0 to 5 mitotic counts per 10 high powered frames (HPFS) at 40 magnification; a score of 2 to represent 6 to 10 mitotic counts per 10 HPFS; and a score of 3 for $>10$ mitotic counts per 10 HPFS. $^{9}$ The extent of tumor necrosis was semi quantitatively assessed and recorded as either absent focal $(\leq 10 \%$ of the tumor area; score 1), moderate $(10 \%$ - $30 \%$; score of 2$)$, or extensive ( $\geq 30 \%$; score of 3). ${ }^{10} \mathrm{~A}$ four-point grading system of inflammatory cells infiltration score was also used as follows: few and focal infiltrations without the formation of aggregates (score 1); multifocal infiltration without lymphoid follicles (score 2); up to three lymphoid follicles or aggregates (score 3); and more than four lymphoid follicles or aggregates (score 4). ${ }^{11}$ After two weeks of the treatment, mice were sacrificed, and the tumors were dissected out, weighed (in grams), their volumes (in $\mathrm{mm}^{3}$ ) were calculated based on length and width dimensions measured by slide calliper. ${ }^{12}$

\section{Statistical analysis}

Statistical Analysis was done by using statistical package computer software. ${ }^{13}$ Analysis of numeric data was performed using one-way analysis of variance (ANOVA). Following ANOVA, the mean of each group was compared with other groups' means by using Fisher's Least Significant Difference (LSD) test. Any difference between any two means larger than the LSD at $P<0.05$ is considered significant. The percentage of necrosis was analyzed using the Chi-square test. $P<0.05$ was considered as the level of significance, and any value more than 0.05 was considered to be non-significant.

\section{Results}

Evaluating histopathological changes in the tumor tissues following different treatment methods were presented in Figures 1- 4. The histopathological features noticed in the various groups of this study were tumor cell proliferation, destructed cells (necrosis), and inflammatory cell infiltration (including lymphocytes and macrophages). Figure 1 summarizes the percent of proliferation in different groups. It was noticed that G11 and G12 showed the lowest proliferative and mitotic tumor cell activity (score of 1). On the other hand, tumors excised from mice receiving treatment of combination therapy of SDT, PDT or SPDT and nano-Chl) in G5, G6, G9 and G10 showed lower percentages of tumor proliferation and mitoses (score of 2), in comparison to G1, G2, G3, and G4. Histopathological findings also revealed that necrosis percentages increased in many treated tumor groups (Figure 2). Furthermore, with high necrosis (score of 3 ), which indicated that the necrotic area was extensive and recorded more than $\geq 30 \%$ in G3, G4, G5, G6, G7, G8, G9, G10, G11 and G12 (Figure 2). Because of the importance of necrosis, which is directly related to the response of the tumor to a different mode of treatment, the study subdivided the percentage of tumor necrosis in a more detailed pattern, as shown in Figure 3. The percent of necrosis ranged from $4 \%$ in $\mathrm{G} 1$ to $95 \%$ of necrotic cells in G12. The histological evaluation revealed that all tumors from the treated groups of mice bearing the tumor showed a statistically significant different percentage of necrosis $(P<0.001)$. 
The tumors excised from animals receiving a combination treatment of SDT, PDT or SPDT and nano-Chl (G5, G6, G9, G10, and G12) showed significantly higher percentages of necrosis compared to SPD treated groups without sensitizer (G3,
G4, G7, and G8). It was also noticed a prominent inflammatory cell infiltration (including lymphocytes and macrophages) beside areas of necrosis in G3, G4, G5, G6, G7, G8, G9, G10, G11 and G12 (inflammation score of 2 ), Figure 4.

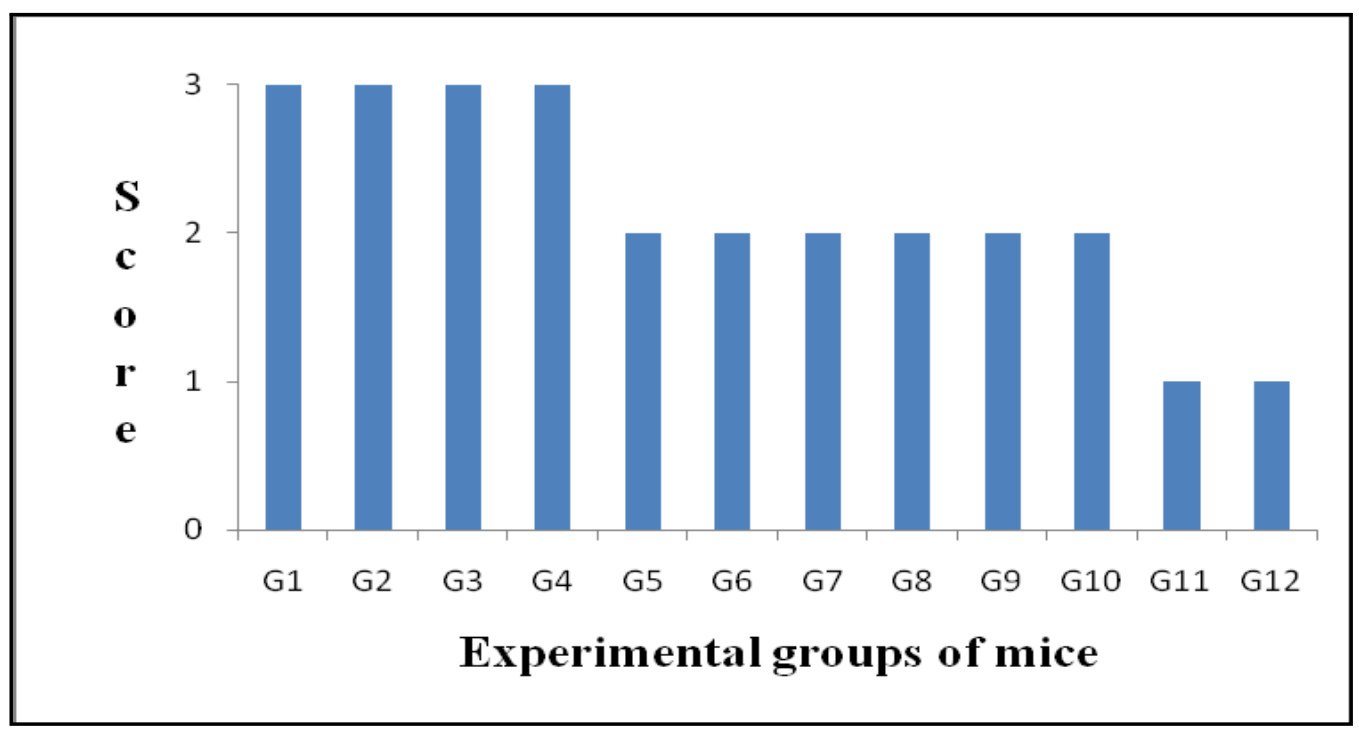

Figure 1: Proliferations scores of the experimental mice groups.

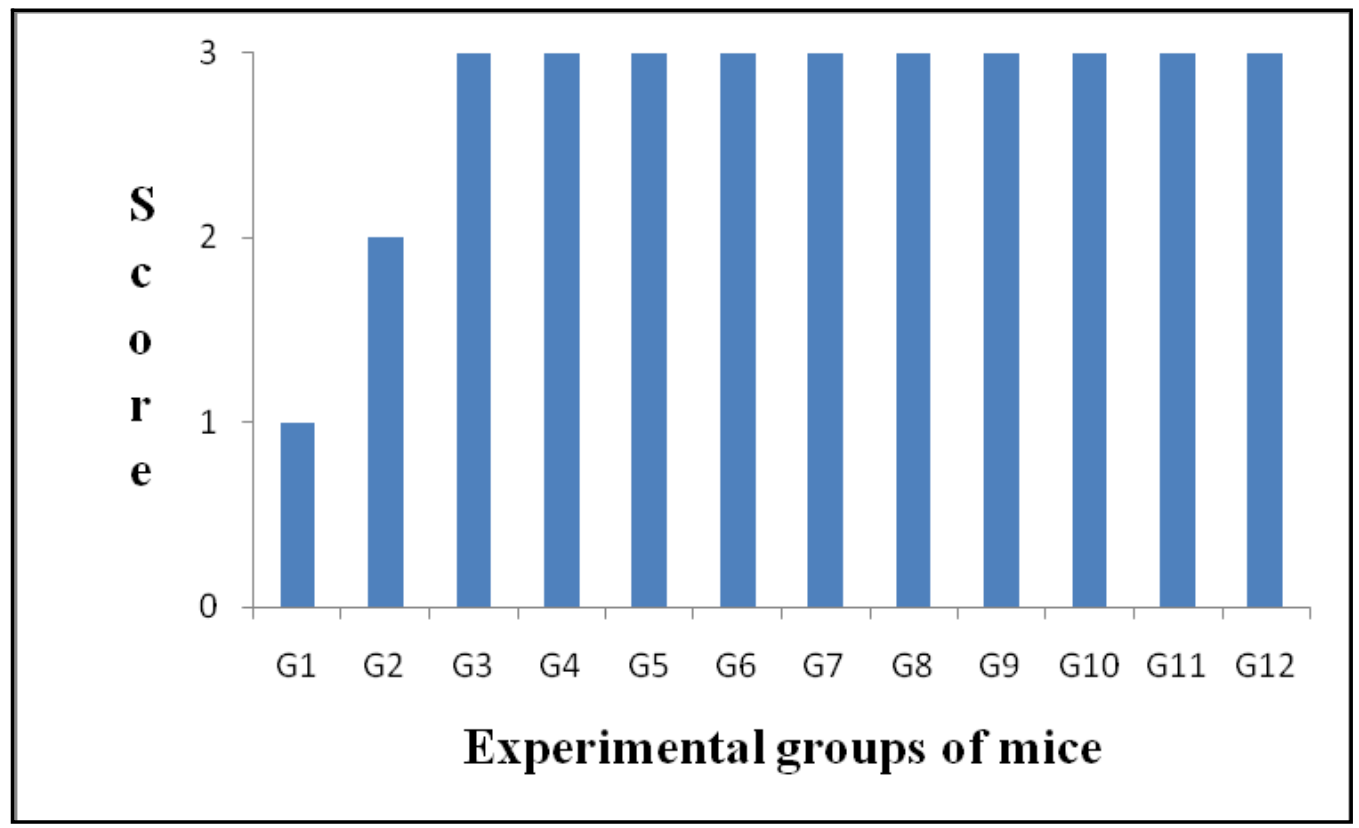

Figure 2: Necrosis scores of the experimental mice groups. 


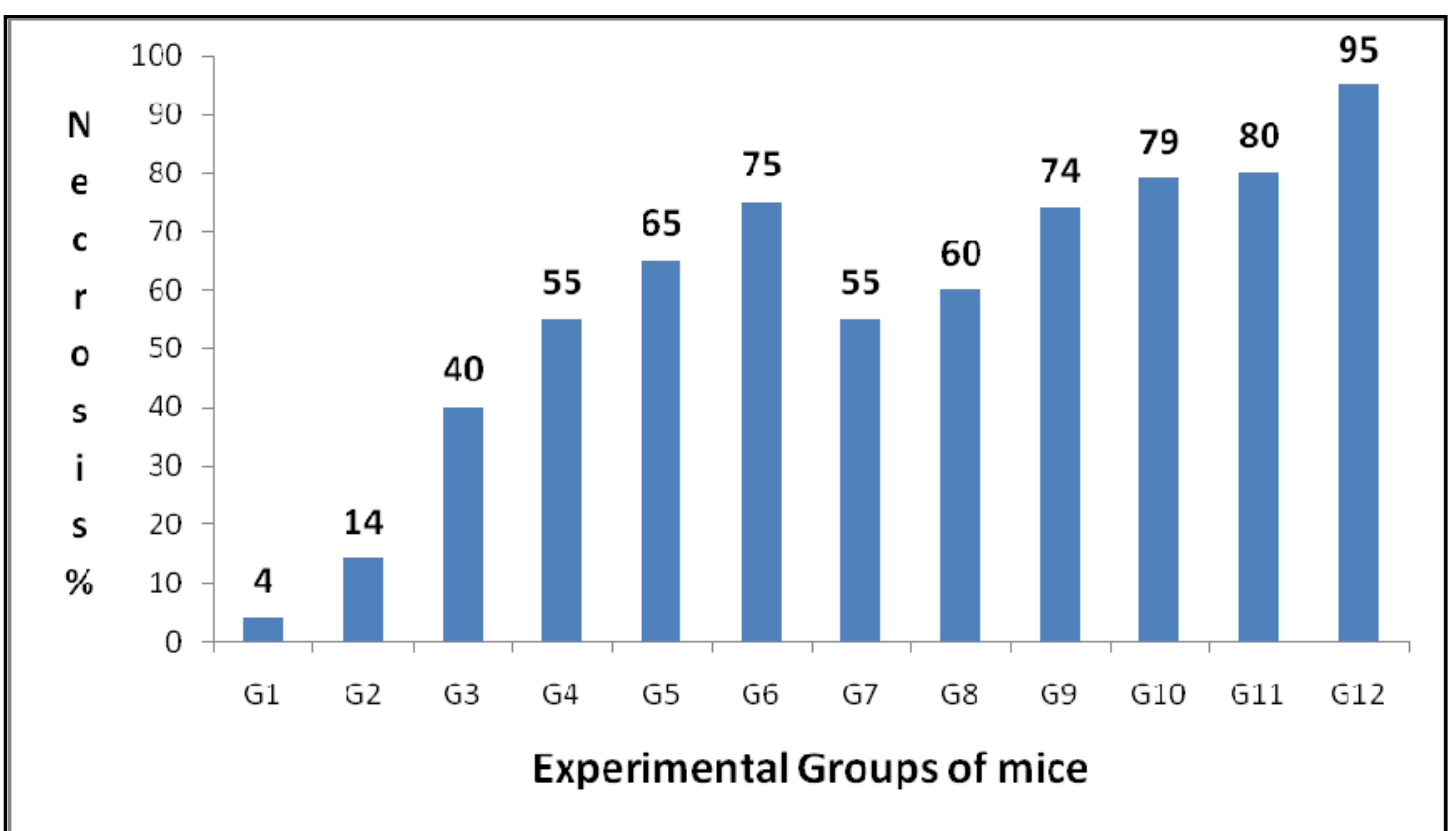

Figure 3. The percent of necrosis in tissues of experimental mice groups (Chi square value $=139, P<0.001)$.

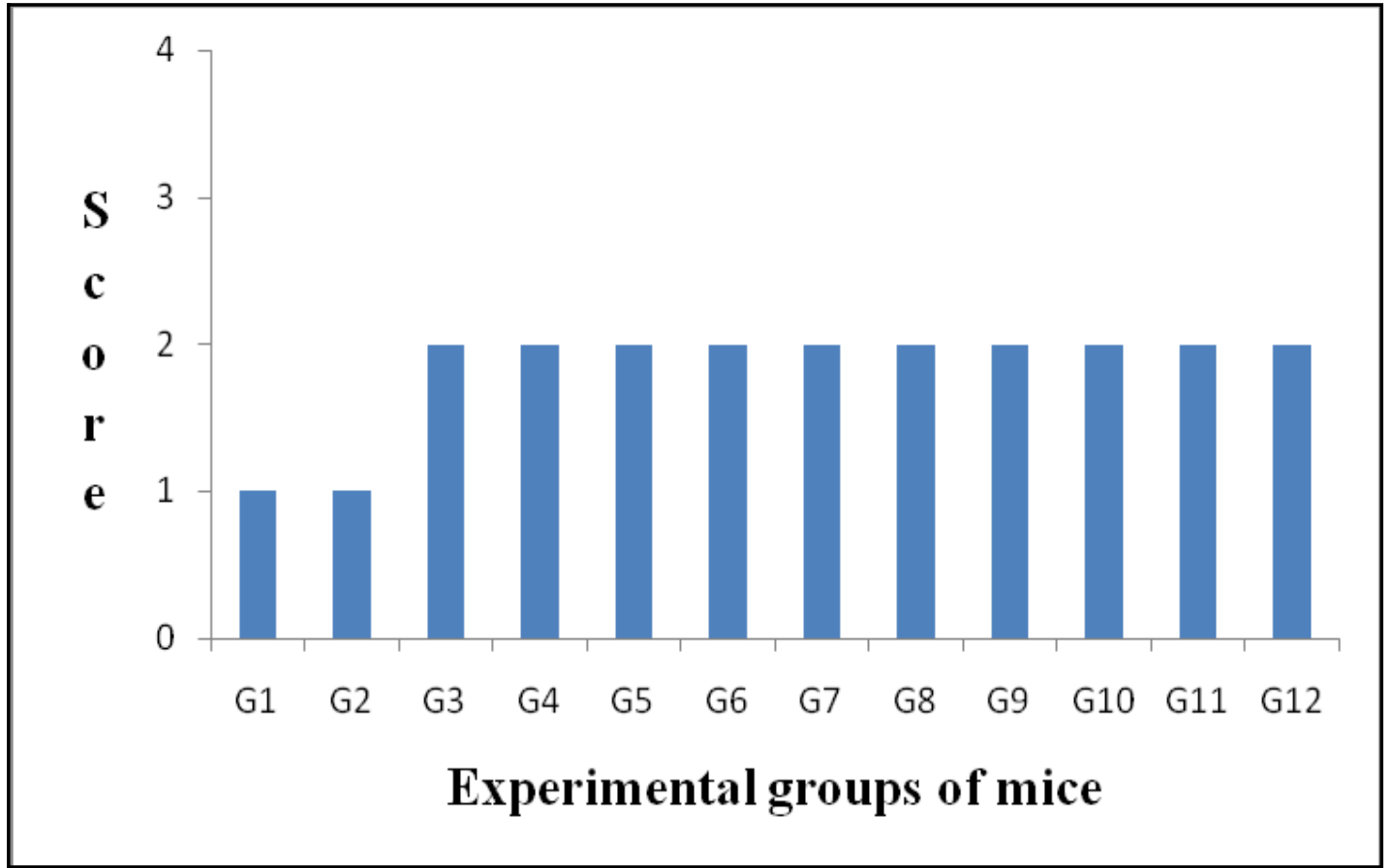

Figure 4: Inflammation scores of the experimental mice groups. 
Histopathological features of tumor seen in the group of mice without treatment (G1) showed prominent tumor cell proliferation and few areas of necrosis (4\%), as in Figure 5. Treated mice group injected IP with
nano-Chl, then the tumor site was irradiated with $4000 \mathrm{~Hz}$ IRL (G5) attained 65\% necrosis, with inflammatory cells infiltration (including lymphocytes and macrophages) within tumor cells (Figure 6).

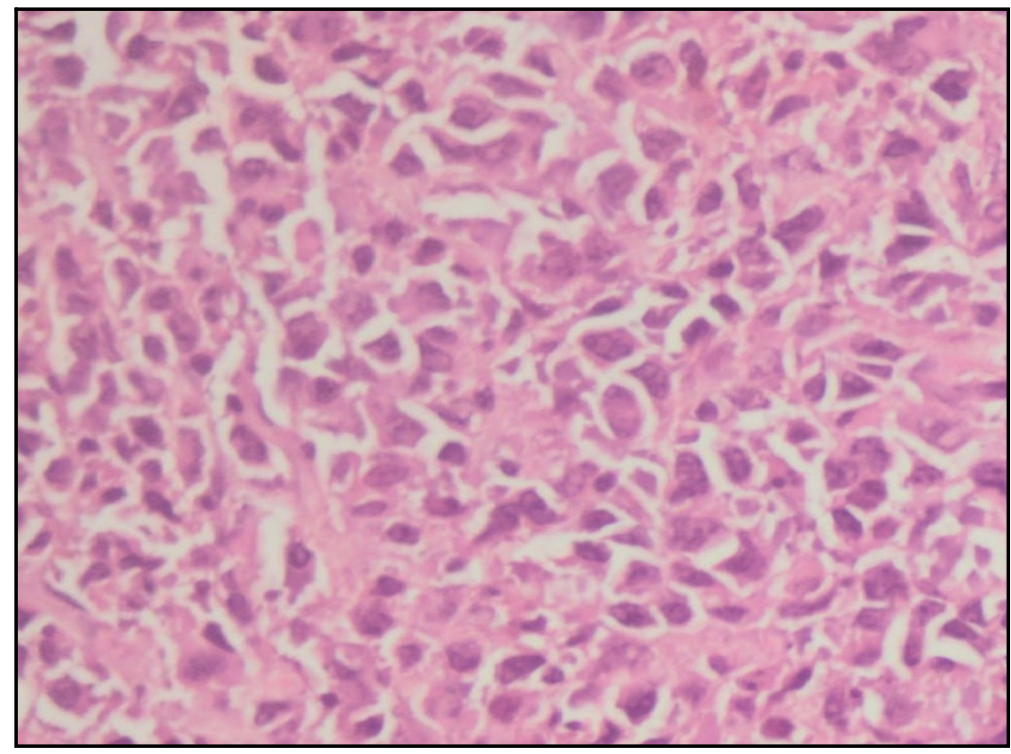

Figure 5: Group of tumor bearing mice (G1) without treatment as a control group [poorly differentiated carcinoma], $\mathrm{H}$ \& E stain $(\times 400)$.

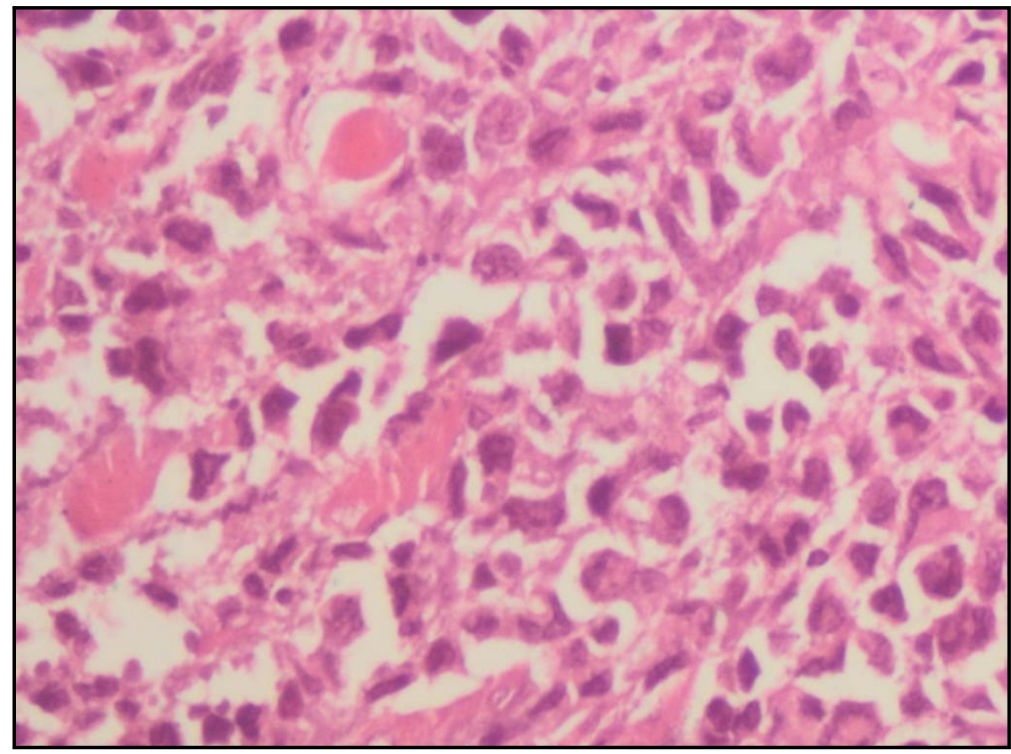

Figure 6: Group of mice (G5) injected IP with (nano-Chl), then the tumor site was irradiated with $4000 \mathrm{~Hz}$ IRL.[Poorly differentiated carcinoma with focal areas of necrosis and scattered inflammatory cells ]. H \& E stain (×400). 
However, the group of mice (G12) injected IP with nano-Chl then the tumor site was irradiated with $7000 \mathrm{~Hz} I R L$ for $3 \mathrm{~min}$, followed by pulsed ultrasound 3 watts for 3 minutes resulted in the highest percentage of necrosis of $95 \%$ with low tumor proliferation as in (Figure 7). The significant differences of tumor volume $\left(\mathrm{mm}^{3}\right)$ between each pair of experimental groups were analyzed based on the least significant difference (LSD) analysis and presented in Table 1. The effects of different treatment modalities were statistically significant compared to the control group (G1). LSD showed a highly significant $P$ value $(P<0.001)$ of tumor volume between $\mathrm{G} 12$ and $\mathrm{G} 1$. Minimum tumor volume was observed in G12 (1.01 $\mathrm{mm}^{3}$ ) compared to the maximum value of G1 $\left(9.13 \mathrm{~mm}^{3}\right)$ (Table 1).

Table 1: Pair wise comparisons of means of tumor volume $\left(\mathrm{mm}^{3}\right)$ based on LSD analysis of mice in the studied groups (ANOVA $P<0.001$ ).

\begin{tabular}{|c|c|c|c|c|c|c|c|c|c|c|c|c|}
\hline \multirow{2}{*}{\multicolumn{2}{|c|}{$\begin{array}{l}\text { Groups I } \\
\text { Tumor volume } \\
\text { means }\left(\mathrm{mm}^{3}\right)\end{array}$}} & \multirow{2}{*}{$\begin{array}{l}\text { G12 } \\
1.01\end{array}$} & \multirow{2}{*}{$\begin{array}{l}\text { G6 } \\
1.87\end{array}$} & \multirow{2}{*}{$\begin{array}{l}\text { G11 } \\
2.2\end{array}$} & \multirow{2}{*}{$\begin{array}{l}\text { G5 } \\
2.45\end{array}$} & \multirow{2}{*}{$\begin{array}{l}\text { G9 } \\
2.66\end{array}$} & \multirow{2}{*}{$\begin{array}{l}\text { G10 } \\
3.11\end{array}$} & \multirow{2}{*}{$\begin{array}{l}\mathbf{G 4} \\
3.51\end{array}$} & \multirow{2}{*}{$\begin{array}{l}\mathbf{G 7} \\
3.75\end{array}$} & \multirow{2}{*}{$\begin{array}{l}\mathrm{G3} \\
4.11\end{array}$} & \multirow{2}{*}{$\begin{array}{l}G 8 \\
4.11\end{array}$} & \multirow{2}{*}{$\begin{array}{l}\text { G2 } \\
8.44\end{array}$} \\
\hline & & & & & & & & & & & & \\
\hline G6 & 1.87 & NS & & & & & & & & & & \\
\hline G11 & 2.2 & 0.05 & NS & & & & & & & & & \\
\hline G5 & 2.45 & 0.01 & NS & NS & & & & & & & & \\
\hline G9 & 2.66 & 0.01 & NS & NS & NS & & & & & & & \\
\hline G10 & 3.11 & 0.001 & 0.05 & NS & NS & NS & & & & & & \\
\hline G4 & 3.51 & 0.001 & 0.001 & 0.01 & 0.05 & NS & NS & & & & & \\
\hline G7 & 3.75 & 0.001 & 0.001 & 0.01 & 0.01 & 0.05 & NS & NS & & & & \\
\hline G3 & 4.11 & 0.001 & 0.001 & 0.001 & 0.001 & 0.01 & 0.05 & NS & NS & & & \\
\hline G8 & 4.11 & 0.001 & 0.001 & 0.001 & 0.001 & 0.01 & 0.05 & NS & NS & NS & & \\
\hline G2 & 8.44 & 0.001 & 0.001 & 0.001 & 0.001 & 0.001 & 0.001 & 0.001 & 0.001 & 0.001 & 0.001 & \\
\hline G1 & 9.13 & 0.001 & 0.001 & 0.001 & 0.001 & 0.001 & 0.001 & 0.001 & 0.001 & 0.001 & 0.001 & NS \\
\hline \multicolumn{13}{|c|}{ Critical value of: } \\
\hline \multirow{2}{*}{\multicolumn{2}{|c|}{$\begin{array}{l}\text { LSD at } P=0.05 \\
\text { LSD at } P=0.01 \\
\text { LSD at } P=0.001\end{array}$}} & $\begin{array}{l}0.95 \\
1.26\end{array}$ & & & & & & & & & & \\
\hline & & 1.59 & & & & & & & & & & \\
\hline
\end{tabular}

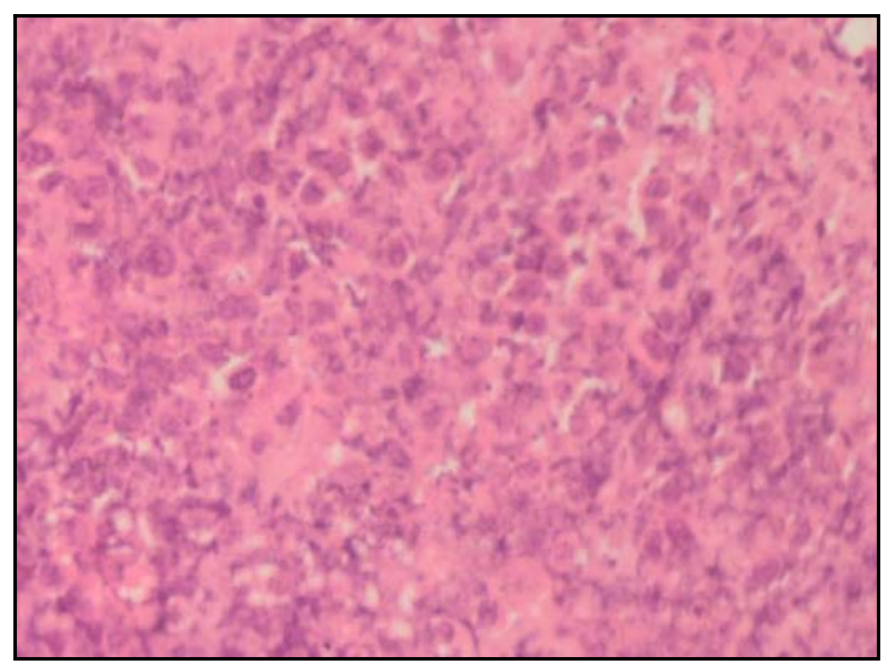

Figure 7: Group of mice (G12) injected IP with (nano-Chl). The tumor site was irradiated with $7000 \mathrm{~Hz}$ IRL for $3 \mathrm{~min}$, followed by pulsed ultrasound 3 watts for 3 minutes [poorly differentiated carcinoma with prominent areas of necrosis] H\&E stain $(\times 400)$. 
Similarly, LSD analysis showed a highly significant $P$ value $(P<0.001)$ of tumor weights between $\mathrm{G} 12$ and $\mathrm{G} 1$. Tumor weights of the therapy treated experimental groups showed low values except for G2 (ranges were between 0.45 to 1.77 for $\mathrm{G} 12$ and G3, respectively (Table 2). Whereas, tumor weights of $\mathrm{G} 2$ (group of tumor bearing mice treated with photosensitizer nano-Chl only) and G1 (group of tumor bearing mice without treatment as a control group) were 6.16 and $6.32 \mathrm{~g}$, respectively. Therefore, tumor volume and tumor weight of the treated experimental mice group (G12) which, injected with nano-Chl and then the tumor site irradiated with $7000 \mathrm{~Hz}$ IRL for $3 \mathrm{~min}$, followed by pulsed ultrasound 3 watts for 3 minutes in the presence of photosensitizer caused a makeable reduction in tumor volume and tumor weight.

\section{Discussion}

The experimental design of this work was set up to evaluate the effectiveness of using SPDT modality in combination with nano-Chl as therapy of choice, through assessment of histopathological features, of EAC implanted in various groups of mice. It is well known that cancer is an abnormal growth of cells, which tend to proliferate in an uncontrolled way. Furthermore, it has been shown that the histopathology approach for predicting drug responsiveness is a standard practice. The results of this study revealed that mice subjected to a combination of PDT and SDT therapy in the presence of nano-Chl showed large foci of tumor cell death (necrosis and apoptosis) with low proliferation and mitoses. Histopathological results of other work also showed large distinct areas of necrosis as well as less proliferation of EAC cells when compared to the control group, ${ }^{14,15}$ which may indicate that Noni (Morinda citrifolia) is one of the important traditional medicinal plants to treat cancer and various neurological

Table 2: Pair wise comparisons of means of tumor weights $(\mathrm{g})$ based on LSD analysis of mice in the studied groups (ANOVA $P<0.001$ ).

\begin{tabular}{|c|c|c|c|c|c|c|c|c|c|c|c|c|}
\hline \multirow{2}{*}{\multicolumn{2}{|c|}{$\begin{array}{l}\text { Groups / } \\
\text { Tumor weights means }\end{array}$}} & \multirow{2}{*}{$\begin{array}{l}\text { G12 } \\
0.45\end{array}$} & \multirow{2}{*}{$\begin{array}{l}\text { G11 } \\
0.64 \\
\end{array}$} & \multirow{2}{*}{$\begin{array}{l}\text { G6 } \\
0.67\end{array}$} & \multirow{2}{*}{$\begin{array}{l}\text { G5 } \\
0.88\end{array}$} & \multirow{2}{*}{$\begin{array}{l}\text { G9 } \\
0.97\end{array}$} & \multirow{2}{*}{$\begin{array}{l}\text { G10 } \\
1.02 \\
\end{array}$} & \multirow{2}{*}{$\begin{array}{l}G 7 \\
1.18 \\
\end{array}$} & \multirow{2}{*}{$\begin{array}{l}\text { G8 } \\
1.45 \\
\end{array}$} & \multirow{2}{*}{$\begin{array}{l}\text { G4 } \\
1.65 \\
\end{array}$} & \multirow{2}{*}{$\begin{array}{l}\mathrm{G} 3 \\
1.77\end{array}$} & \multirow{2}{*}{$\begin{array}{l}\mathrm{G} 2 \\
6.16\end{array}$} \\
\hline & & & & & & & & & & & & \\
\hline G11 & 0.64 & NS & & & & & & & & & & \\
\hline G6 & 0.67 & NS & NS & & & & & & & & & \\
\hline G5 & 0.88 & NS & NS & NS & & & & & & & & \\
\hline G9 & 0.97 & NS & NS & NS & NS & & & & & & & \\
\hline G10 & 1.02 & NS & NS & NS & NS & NS & & & & & & \\
\hline G7 & 1.18 & NS & NS & NS & NS & NS & NS & & & & & \\
\hline G8 & 1.45 & NS & NS & NS & NS & NS & NS & NS & & & & \\
\hline G4 & 1.65 & 0.05 & NS & NS & NS & NS & NS & NS & NS & & & \\
\hline G3 & 1.77 & 0.05 & 0,05 & 0.05 & NS & NS & NS & NS & NS & NS & & \\
\hline G2 & 6.16 & .001 & .001 & .001 & .001 & .001 & .001 & .001 & .001 & .001 & .001 & \\
\hline G1 & 6.32 & .001 & .001 & .001 & .001 & .001 & .001 & .001 & .001 & .001 & .001 & NS \\
\hline \multicolumn{12}{|c|}{ Critical value of: } & 1.05 \\
\hline \multicolumn{2}{|c|}{$\begin{array}{l}\mathrm{LSD} \text { at } P=0.05 \\
\mathrm{LSD} \text { at } P=0.01\end{array}$} & \multicolumn{11}{|c|}{1.39} \\
\hline
\end{tabular}


disorders. ${ }^{16}$ PDT has proved to be a viable and interesting alternative to currently used methods for palliative care of cancer and, in a limited number of cases, for curative treatment. Nevertheless, in spite of impressive progress and approval of clinical therapy strategies applications, the great potential of PDT has not yet been fully realized because of current deficiencies of applied sensitizers. Introduction of chlorophyll- and bacteriochlorophyll-derived sensitizers is expected to markedly change this situation in the coming decade. ${ }^{17}$ Previous research results indicated that photodynamic therapy had been used for more than 100 years to treat tumors. The goal of PDT therapy research is to enhance the selective targeting of tumor cells in order to reduce the risk and extension of unwanted side-effects that damage normal cells. The results of this study are in agreement with that reported earlier, which revealed that SPDT therapy combined with sonosensitive agent's sensitizers is suitable for cancer therapy and is a promising treatment for patients with cancer. ${ }^{18-21}$ Furthermore, it has been reported that cancer is a serious threat to human health, and it is one of the major killers. The treatment of cancer has attracted more and more attention. Currently, the means of treating cancer is also increasing, but there is no emergence of fully satisfactory treatment. A combination of SDT therapy and PDT or SPDT, is a new composite cancer therapy. This conclusion is supporting to that found in the present study as SPDT therapy can significantly improve the tumor curing effect, and has good application prospects in cancer treatment. ${ }^{22}$ SDT and PDT therapy can penetrate deeply into tissues and can be focused into a small region of a tumor to activate the cytotoxicity of sonosensitizers. This is a unique advantage in the non-invasive treatment of nonsuperficial tumors when compared to laser light used for PDT. For the similar mechanism of PDT and SDT, it was hypothesized that SDT may be exploited for the generation of effective therapeutic cancer vaccines like PDT; and a combination of SDT with Immunoadjuvant may be a promising systemic treatment modality, not only for superficial cancers but also for deep-seated tumors, which would surpass PIT. ${ }^{23}$ A research was conducted aiming at cancer targeted therapy using the SPDT therapy in combination with sonnelux (SLux) as a sono-photosensitizer. Two sources of energy were used; namely infrared laser and Ultrasound (pulsed and continuous wave mode). Results revealed that nano-SLux is a potential photosensitizer and sonsensitizer for photodynamic or SDT treatment of Ehrlich ascites tumor tissue, which played important roles in inhibiting tumor growth and even inducing cell death, which might be attributed to photo and/or sono-chemical activation mechanism. Infra -red laser in combination with ultrasound in the presence of sensitizer has a potential antitumor effect. ${ }^{24}$ Nevertheless, the result of the present study showed a marginal increase in the necrotic area, usually those towards the center of the tumor, which may be due to cell injury, leading to the development of a necrotic core of dead cells. Such results confirmed by other research. ${ }^{25} \mathrm{~A}$ research study revealed that each tumor develops a three-layer structure: a necrotic core, surrounded by a layer of quiescent cells, which is, in turn, surrounded by a thin proliferating rim. $^{26}$ Moreover, the results of the present study observed the effect of SPD modality in combination with nano-Chl as a sonophoto sensitizer in decreasing both tumor volume and weight. This result confirmed that of Bhattacharyya, ${ }^{27}$ who stated that mechanisms of apoptogenic effect on Ehrlich's ascites carcinoma bearing Swiss albino mice are prominent by a significant decrease in tumor volume. Present results also noticed inflammatory cell infiltration, including lymphocytes and macrophages beside areas of necrosis especially above $65 \%$ field of necrosis, which may indicate the effectiveness of the injected IP nano-Chl and 
more intense when combined with pulsed or continuous ultrasound and irradiated by 7000 $\mathrm{Hz}$ IRL. Therefore, the results of this study suggest the additive and synergistic activity of SPD with nano-Chl being significantly caused by higher anti cancer activities. This enhancement may produce some cytokinetic products such as interleukin, tumor necrosis factors, and interferon, which in turn may be responsible for destroying tumor cells. This result may be of interest to advanced cancer researches in the future. The findings of the present study confirm the previous results reported earlier. ${ }^{28}$ Furthermore, another study indicated that the differential count of white blood cells showed an increase in the percentage of neutrophils, alteration in signal transduction of tumor growth, and stimulation of apoptosis in tumor cell lines were noticed. They also have been shown to enhance peripheral blood lymphocyte and T-cell proliferation, which suggests a possible stimulation of the immune system function. ${ }^{29}$

\section{Conclusion}

The group of animals subjected to a combination of photodynamic and SDT therapy in the presence of nano-Chl, showed large foci of necrotic areas as well as a remarkable reduction in tumor volume and tumor weight at the end of two weeks of therapy. It is recommended that further research for the isolation of ingredients and the establishment of the mode of action that was actively responsible for the anticancer activity of nano-Chl.

\section{Competing interests}

The authors declare no competing interests.

\section{References}

1. American Cancer Society, Inc. Radiation Therapy Basics; 2018. (Accessed April 8, 2018, at https://cancer.org/treatment/treatments-and-sideeffects/treatment-types/radiation/basics).

2. Anand $P$, Kunnumakara $A B$, Sundaram $C$, Harikumar KB, Tharakan ST, Lai OS, et al. Cancer is a preventable disease that requires major lifestyle changes. Pharmaceut Res 2008;
25:2097-116.

3. Arora S, Jain J, Rajwade JM, Paknikar $\mathrm{KM}$, Cellular responses induced by silver nanoparticles: In vitro studies. Toxicol Lett 2008; 179:93-100.

4. Mohamed MM, Mohamed MA, Fikry NM. Enhancement of antitumor effects of 5-fluorouracil combined with ultrasound on Ehrlich ascites tumor in vivo. Ultras Med Boil 2003; 29:1635-43.

5. Paliwal S, Mitragotri S. Ultrasound-induced cavitation: applications in drug and gene delivery. Expert Opinion Drug Deliv 2006; 3:713-26.

6. Larry L. Chlorophyll. Biology Dictionary. Organ; 2014. (Accessed April 2, 2018, at https://biologydictionary.net/organ/).

7. Dalecki D, Mechanical bioeffects of ultrasound. Annu Rev Biomed Eng 2004; 6:229-48.

8. Salem ML, Eissa IR, Mohamed, TM. Dendritic cells generated from naïve and tumor-bearing mice uniquely restores different leukocyte subpopulations in chemotherapy-treated tumorbearing mice. Clinical cancer Investigation J 2016; 5(1):1-10.

9. Mitko V, Yujing JH, Nikolas S, Babak EB, Francisco B, Thomas W, et al. Predicting breast tumor proliferation from whole-slide images: TUPAC16. The challenge 2016. https://arxiv.org/ pdf/1807.08284.

10. Pollheimer MJ, Kornprat $P$, Lindtner RA, Harbaum L, Schlemmer A, Rehak $P$, et al. Tumor necrosis is a new promising prognostic factor in colorectal cancers. Human Pathology 2010; 41(12):1749-57.

11. Kim YW, Jan KM, Jung DH, Cho MY, Kim NK. Histological inflammatory cell infiltration is associated with the number of lymph nodes retrieved in colorectal cancer. Anticancer Res 2013; 33(11):5143-50.

12. John PF, Ron G, Shlomo M, Jeremy S, Itzhak O. A mathematical model for tumor volume evaluation using two-dimensions. J Applied Quantitative Methods 2009; 4(4):455-62.

13. GraphPad Software, Inc.2018.7825 Fay Avenue, Suite 230, La Jolla, CA 92037 USA. (Accessed April 6, 2018, at https://www.graphpad.com/ scientific-software/prism/).

14. Rafal A. Is medical research at the right track? Global Journal of Medical Research. K Interdisciplinary 2016; 16(6):1-7.

15. Hariom S, Saswata B, Saumen K, Tapan K C. Overview of freeze dried andaman noni (morinda citrifolia.I) against cancer and neurological disorder. Inter. J Pharmaceut Sci Res 2015; 6(4):1342-50.

16. Singh A K. Descriptors for Noni, Morinda citrifolia L. WNRF Technical Bulletin - 01. World Noni Research Foundation, Chennai, India; 2010. (Accessed April 20, 2018, at h t t p s : / / w w w . rese a r chg a te.net/ publication/322116452). 
17. Alexander SB, Yoram S, Avigdor S. Chlorophyll Sensitizers in Photodynamic Therapy. Part of the Advances in Photosynthesis and Respiration book series. AIPH 2017; 25:461-83.

18. Sadanala KC, Chaturvedi PK, Seo YM, Kim JM, Jo YS, Lee YK, et al. Sono-photodynamic combination therapy: a review on sensitizers. Anticancer Res 2014; 34(9):4657-64.

19. Ray C, Chin-Feng H, Wei-Bor T. Fabrication of chlorophyll-incorporated nanogels for potential applications in photothermal cancer therapy. ACS Omega 2018; 3(11):16057-62.

20. Gupta A, Wang S, Marko A, Joshi P, Ethirajan M, Chen Y, et al, Polyacrylamide-based biocompatible nanoplatform enhances the tumor uptake, PET/fluorescence imaging and anticancer activity of a chlorophyll analog. Theranostics 2014; 4(6):614-28.

21. Hongyue Z, Wenting L, Guanghui T, Guohua D, Zhiqiang W, Yingxue J. The anti-cancer potency of photodynamic therapy of a novel chlorin derivative Amidochlorin p6 (ACP). Royal Society of Chemistry 2017; 7:40873-80.

22. Krishna C S, Pankaj $\mathrm{K}$ C, You M S, Jeung $M$ K, Yong $S$ J, Yang $K$ L, et al. Review Sono-Photodynamic Combination Therapy: A Review on Sensitizers. Anticancer Research 2014; 34:4657-64.

23. Ma X, Pan H, Yi J. Combination sonodynamic therapy with immunoadjuvant may be a promising new modality for cancer treatment. Med Hypotheses 2009; 72(4):418-20.

24. Abd El-Kaream SA, Abd Elsamie GH, Abd-Alkareem AS. Sono-photodynamic modality for cancer treatment using bio-degradable bio-conjugated sonnelux nanocomposite in tumor -bearing mice: Activated cancer therapy using light and ultrasound. Biochem Biophys Res Commun 2018; 5:503(2):1075-86.

25. Proskuryakov SY, Konoplyannikov AG, Gabai VL. Necrosis: A specific form of programmed cell death. Exp. Cell Res 2003; 283(1):1-16.

26. Dorothy IW, Xinyue G. Properties of tumor spheroid growth exhibited by simple mathematical models. Front Oncol 2013; 3:5162.

27. Bhattacharyya A, Choudhuri T, Pal S, Chattopadhyay S, K Datta G, Sa G, et al. Apoptogenic effects of black tea on Ehrlich's ascites carcinoma cell. Carcinogenesis 2003; 24:1:75-80,

28. Shaikh M M, Abul Kalam MA, Mele J, Shamim A, Mijanur R, Jahan AK, et al. In vivo anticancer activity of vanillin semicarbazone. Asian Pac J Trop Biomed 2012; 12:60072-80.

29. Muralidhar A, Somasekhar A, Sumanjali A, Praveen B, Lakshmi BP, Shahdul Vali TC, et al. Anticancer activity of Tephrosia purpurea root extracts against Ehrlich Ascites Carcinoma (EAC) cells in Swiss albino mice. Der Pharmacia Sinica 2014; 5(2):81-7. 